\title{
$A b$ Initio Investigation of the Kinetics and Mechanism of the Neutral Hydrolysis of Formamide in Aqueous Solution
}

\author{
Gizelle I. Almerindo and Josefredo R. Pliego Jr. ${ }^{*}$
}

Departamento de Química, Universidade Federal de Santa Catarina, 88040-900, Florianópolis-SC, Brazil

\begin{abstract}
A hidrólise neutra da formamida em solução aquosa foi investigada por métodos $a b$ initio de alto nível, incluindo o efeito do solvente pelo modelo contínuo polarizável (PCM). Considerou-se até quatro moléculas explícitas de água, sendo analisados os mecanismos envolvendo a formação do intermediário tetraédrico (stepwise mechanism) e o mecanismo de formação direta do ácido carboxílico via expulsão de amônia (concerted mechanism), estes com a participação de moléculas de água agindo como um catalisador bifuncional. Também foi investigado um mecanismo de catálise básica geral, com uma molécula de água agindo como base. Os cálculos em nível CCSD(T)/6-311+G(2df,2p)/ /MP2/6-31G(d) predizem que o mecanismo stepwise com duas moléculas de água no estado de transição é o mais favorável. Porém, a barreira de energia livre de $48,7 \mathrm{kcal} \mathrm{mol}^{-1}$ indica que a cinética é extremamente lenta e a reação não seria observada. Também analisamos o efeito do solvente sobre a geometria do estado de transição e notamos que esse efeito é de pouca importância na barreira energética. Testes com a teoria do funcional da densidade, usando o funcional B3LYP, mostram que conjuntos pequenos de funções de base como 6-31G(d) leva a barreiras de ativação extremamente subestimadas, enquanto que o uso do conjunto de funções de base 6-311+G(2df,2p) prevê barreiras próximas ao nosso melhor nível de cálculo. O presente estudo levanta dúvidas com relação a barreira experimental de $31 \mathrm{kcal} \mathrm{mol}^{-1}$ e sugerimos que a constante cinética $\mathrm{k}_{\mathrm{w}}$ reportada na literatura seja apenas um artefato matemático oriundo do ajuste de curvas.
\end{abstract}

The neutral hydrolysis of formamide in aqueous solution involving up to four explicit solvent molecules was theoretically investigated using high level $a b$ initio methods and including the bulk solvent effect through the Polarizable Continuum Model (PCM). We have analyzed cyclic transition states structures involving bifunctional catalysis and a general base catalysis structure. Both a stepwise mechanism with tetrahedral intermediate formation and a concerted mechanism were investigated. Our calculations at $\operatorname{CCSD}(\mathrm{T}) / 6-311+\mathrm{G}(2 \mathrm{df}, 2 \mathrm{p}) / / \mathrm{MP} 2 / 6-31 \mathrm{G}(\mathrm{d})$ level predict an observable activation free energy barrier of $48.7 \mathrm{kcal} \mathrm{mol}^{-1}$, corresponding to a stepwise water catalyzed mechanism with two water molecules into the transition state. Liquid phase geometry optimization was also performed, but the effect on the activation free energy is modest. Tests with density functional theory were carried out. The B3LYP/6-31G(d) calculation underestimates the barrier by $13 \mathrm{kcal} \mathrm{mol}^{-1}$, whereas the B3LYP/6-311+G(2df,2p) method predicts an accurate barrier. The present study raises important questions about the reliability of the experimental activation free energy of $31.0 \mathrm{kcal} \mathrm{mol}^{-1}$ and suggests that the neutral hydrolysis of formamide does not take place at all.

Keywords: amide hydrolysis, ab initio, reaction mechanism, bifunctional catalysis

\section{Introduction}

The amide functional group plays a central role in biochemistry and the knowledge of its stability and reaction mechanisms in aqueous solution are very important goals. The hydrolysis reaction is catalyzed by both acids and bases ${ }^{1,2}$ but another reaction pathway is

*e-mail: josef@netuno.qui.ufmg.br

Present address: Departamento de Química, Universidade Federal de Minas Gerais, 31270-901 Belo Horizonte-MG possible: the neutral or water catalyzed hydrolysis. Scheme 1 illustrates these three reaction pathways.

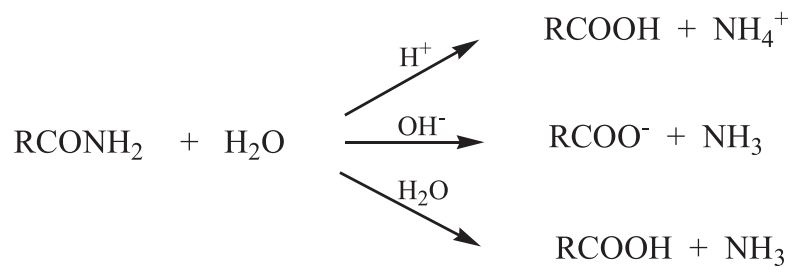

Scheme 1. 
Based on this scheme, the observable pseudo-firstorder rate constant will be given by:

$$
\mathrm{k}_{\mathrm{obs}}=\mathrm{k}_{\mathrm{H}^{+}}\left[\mathrm{H}^{+}\right]+\mathrm{k}_{\mathrm{OH}^{-}}\left[\mathrm{OH}^{-}\right]+\mathrm{k}_{\mathrm{W}}
$$

The neutral hydrolysis is very slow and it is not readily observed unless we are considering reactions involving activated amides such as $p$-nitrotrifluoroacetanilide. ${ }^{3}$ However, in the case of formamide, some experimental studies suggest that the neutral hydrolysis is kinetically meaningful. ${ }^{4,5}$ Indeed, Hine et al. ${ }^{5}$ have studied the hydrolysis of formamide at $80{ }^{\circ} \mathrm{C}$ as a function of the $\mathrm{pH}$ and although it was not found a plateau in the $\mathrm{pH}$-rate profile, which corresponds to the neutral hydrolysis, they have obtained that the kinetics expression including the neutral hydrolysis term $\left(\mathrm{k}_{\mathrm{w}}\right)$ increases the quality of the fitting to experimental data. More recently, Brown and co-workers ${ }^{4}$ have studied this same reaction system at $56^{\circ} \mathrm{C}$ and $120^{\circ} \mathrm{C}$. Again, no plateau was observed, but the fitting of the rate equation to the experimental data was better including the neutral hydrolysis term. These authors have estimated that at $25^{\circ} \mathrm{C}$, the rate constant for the neutral hydrolysis of formamide in aqueous solution is $1.1 \times 10^{-10} \mathrm{~s}^{-1}$, which translates to an activation free energy barrier of $31.0 \mathrm{kcal} \mathrm{mol}^{-1}$.

Theoretical studies of the neutral hydrolysis of amides have been reported in the past twenty years and the results of these studies do not support the experimental analysis. ${ }^{6-13}$ Both the pathway of formation of the tetrahedral intermediate (stepwise mechanism) and the pathway through the direct elimination of ammonia (concerted mechanism), presented in Scheme 2, were investigated. An early MP4(SDQ)/6-31G(d,p)//HF/3-21G study of the reaction of one water molecule with formamide in gasphase by Oie et al..$^{13}$ has predicted a $\Delta \mathrm{G}^{\circ \neq}=55.3 \mathrm{kcal} \mathrm{mol}^{-1}$ for the stepwise mechanism, and $57.5 \mathrm{kcal} \mathrm{mol}^{-1}$ for the concerted mechanism. Posterior studies by Bader et al. ${ }^{12}$ and Antonczak et al. ${ }^{10}$ for the concerted mechanisms, have confirmed this high energy barrier. In addition, Antonczak and coworkers have analyzed the catalysis of this reaction by a second water molecule (concerted water catalyzed mechanism) and even in this case, the barrier remains very high, $48.4 \mathrm{kcal} \mathrm{mol}^{-1}$ at MP2/6-31G(d,p)//HF/3-21G level.

Kallies and Mitzner ${ }^{7}$ have also done an investigation of the neutral hydrolysis of formamide at B3LYP/6-31G(d) level of theory, including up to three water molecules in the transition states and solvating this cluster by the bulk solvent using a continuum solvation model. The activation free energy barrier for the stepwise water catalyzed mechanism was calculated as being $45.7 \mathrm{kcal} \mathrm{mol}^{-1}$, while for the concerted water catalyzed mechanism, the barrier

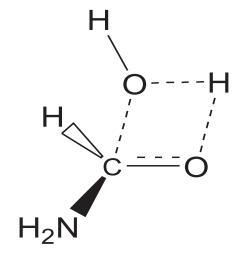

Stepwise

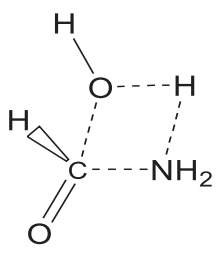

Concerted

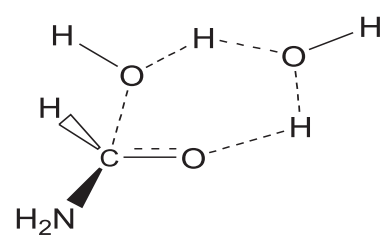

Stepwise water catalyzed<smiles>O=C1CC1O</smiles>

Concerted water catalyzed
Scheme 2.

was $48.1 \mathrm{kcal} \mathrm{mol}^{-1}$. More recently, a sophisticated theoretical multiple-steering ab initio molecular dynamics calculation have also been utilized in the investigation of the neutral hydrolysis of formamide by Cascella and co-workers. ${ }^{6}$ They have reported an activation barrier of $44 \mathrm{kcal} \mathrm{mol}^{-1}$ with a BLYP functional in the Car-Parrinello molecular dynamics calculations.

In the above discussion, it is evident that there is a disagreement between theoretical and experimental results regarding the neutral hydrolysis of formamide. In addition, it should be noticed that several authors have reported their theoretical activation free energy using $1 \mathrm{~atm}$ as standard state $\left(\Delta \mathrm{G}^{\circ *}\right)$, rather than $1 \mathrm{~mol} / \mathrm{L}\left(\Delta \mathrm{G}^{\ddagger}\right)$, which is used in the present calculations. These choices of the standard state can lead to quite different calculated properties such as $\mathrm{pK}_{\mathrm{a}}{ }^{14-16}$ as well as, activation free energies. Furthermore, relatively small basis sets were used in the calculation of energies, a fact that raises questions about the reliability of the previous studies. Hence, this important system deserves a careful and accurate theoretical investigation in order to provide a trustful answer for two questions: 1) Does the neutral hydrolysis of formamide in aqueous solution take place or not? 2) What is the true reaction mechanism? The aim of the present work is to address these questions.

\section{Calculations}

The first step of the reaction between formamide and one, two, three and four water molecules, leading to the formation of the tetrahedral intermediate, was investigated by $a b$ initio calculations. We have done a 
more detailed analysis of the stepwise mechanism because previous studies have shown that this pathway has the lowest activation barrier. ${ }^{7,13}$ The concerted mechanism was also investigated including two water molecules. The geometries of minima and transition states were determined by full optimization at MP2/6$31 \mathrm{G}(\mathrm{d})$ level. This same method was used in the computation of the harmonic frequencies to verify the nature of the stationary points and to obtain the thermodynamic properties by statistical mechanics calculations. In order to include a higher level of electron correlation, we have done calculations at $\operatorname{CCSD}(\mathrm{T}) / 6$ $31 \mathrm{G}(\mathrm{d})$ and MP2/6-311+G(2df,2p) levels, and these data was used in the additivity approximation to obtain an effective CCSD(T)/6-311+G(2df,2p) level of theory. Additional computations were done at MP2 level with aug-cc-pVDZ, aug-cc-pVTZ and aug-cc-pVQZ in order to analyze the saturation of the basis set. We have also tested the performance of density functional theory through calculations using the B3LYP functional with 6-31G(d) and 6-311+G(2df,2p) basis sets.

The gas-phase-optimized structures were allowed to interact with a dielectric continuum to include the solvent contribution for the activation barriers. The polarizable continuum model (PCM) of Tomasi and co-workers ${ }^{17-19}$ was utilized for solvation in aqueous solution. We have used the fixed atomic radius (1.20 for $\mathrm{H}, 1.50$ for $\mathrm{O}$, 1.60 for $\mathrm{N}$ and 1.70 for $\mathrm{C}$ ) which are default in the Gamess program and a scale factor of 1.20. The integral equation formalism (IEF) routine ${ }^{20,21}$ was used in the calculations, in conjunction with a HF/6-31+G(d) wave function. Electrostatic and nonelectrostatic contributions were included. It should be noticed that a recent study has shown that reactions with three and possibly more molecules into the transition state may have a substantial effect of the nonelectrostatic solvation on the activation free energy. ${ }^{22}$ For the concerted water catalyzed mechanism, we have also analyzed the role of the solvent on the transition state geometry. Thus, further optimization was done using the PCM method with the B3LYP/6-31+G(d) wave function.

In the reported thermodynamics data, the standard state of $1 \mathrm{~mol} \mathrm{~L}^{-1}$ and $298.15 \mathrm{~K}$ have been utilized. The relation between the activation free energy in this standard state $\left(\Delta \mathrm{G}^{\ddagger}\right)$ and in the standard state of $1 \mathrm{~atm}\left(\Delta \mathrm{G}^{\circ}\right)$ are related through the expression:

$\Delta \mathrm{G}^{\ddagger}=\Delta \mathrm{G}^{\text {o‡ }}-\left(1.89 \mathrm{kcal} \mathrm{mol}^{-1}\right) \times \mathrm{n}$

where $\mathrm{n}$ is the number of water molecules in the transition state. The calculations were done using the PC Gamess version ${ }^{23}$ of the Gamess United States Quantum Chemistry program, ${ }^{24}$ as well as through the $\operatorname{CCSD}(\mathrm{T})$ routines ${ }^{25,26}$ of the Gamess program. The additional single point MP2 and B3LYP calculations were performed with the Gaussian 98 system, ${ }^{27}$ while the converged liquid-phase PCM/ B3LYP/6-31+G(d) and gas-phase B3LYP/6-31+G(d) optimizations were done with the new routines available in the Gamess program using the number of tesserae 240 for each atom. For liquid-phase optimizations, the maximum gradient was converged to 0.0004 au.

In order to make an adequate comparison with experimental data, it is important to notice that in aqueous solution, the number of explicit water molecules active in the transition state is not available from experimental data. The experimental activation thermodynamic properties are reported considering the neutral hydrolysis as an unimolecular process. Thus, the theoretical activation data such as $\Delta \mathrm{G}_{\text {sol }}^{\ddagger}$, the solution phase activation free energy $\left(1 \mathrm{~mol} \mathrm{~L}^{-1}\right.$ as standard state), have to be transformed to an observable activation free energy, $\Delta \mathrm{G}_{\mathrm{obs}}^{*}$. Considering that $n$ water molecules are active in the transition state, the reaction rate can be written as:

$$
\frac{\mathrm{d}[\text { product }]}{\mathrm{dt}}=\mathrm{k}_{\mathrm{n}}\left[\mathrm{H}_{2} \mathrm{O}\right]^{\mathrm{n}}\left[\mathrm{HCONH}_{2}\right]
$$

Because this reaction occurs in aqueous solution, the water concentration term is constant and $\left[\mathrm{H}_{2} \mathrm{O}\right]=55.5$ mol L ${ }^{-1}$. Thus, the observable pseudo-first-order rate constant will be:

$\mathrm{k}_{\mathrm{obs}}=\mathrm{k}_{\mathrm{n}}\left[\mathrm{H}_{2} \mathrm{O}\right]^{\mathrm{n}}$

Based on transition state theory, the real rate constant $\left(\mathrm{k}_{\mathrm{n}}\right)$ can be calculated through the relationship:

$\mathrm{k}_{\mathrm{n}}=\frac{\mathrm{kT}}{\mathrm{h}} \mathrm{e}^{-\Delta \mathrm{G}_{\mathrm{sol}}^{*} / \mathrm{RT}}$

and using equations (4) and (5), we can relate the theoretically calculated activation free energy $\left(\Delta \mathrm{G}_{\text {sol }}^{\ddagger}\right)$ with the observable rate constant $\left(\mathrm{k}_{\mathrm{obs}}\right)$ and observable activation free energy $\left(\Delta \mathrm{G}_{\mathrm{obs}}^{+}\right)$by the equations below:

$\mathrm{k}_{\mathrm{obs}}=\frac{\mathrm{kT}}{\mathrm{h}} \mathrm{e}^{-\Delta \mathrm{G}_{\mathrm{obs}}^{*} / \mathrm{RT}}$

$\Delta \mathrm{G}_{\mathrm{obs}}^{\ddagger}=\Delta \mathrm{G}_{\text {sol }}^{\ddagger}-\mathrm{nRT} \ln \left[\mathrm{H}_{2} \mathrm{O}\right]$

These equations were used in order to compare our theoretical data with the experimental one. 


\section{Results}

The full-optimized geometries of the transition states, located at MP2/6-31G(d) level of theory, are presented in Figure 1. Table 1 shows the activation thermodynamic properties calculated using single point energies at MP2 and $\operatorname{CCSD}(\mathrm{T})$ levels with the $6-31 \mathrm{G}(\mathrm{d})$ and $6-311+\mathrm{G}(2 \mathrm{df}, 2 \mathrm{p})$ basis sets. The transition state involving one water molecule and corresponding to the stepwise mechanism (TS1a) leads to an activation free energy barrier of $50.6 \mathrm{kcal} \mathrm{mol}^{-1}$ in gas-phase, and including the solvent effect the barrier increases to 55.2 $\mathrm{kcal} \mathrm{mol}^{-1}$. This value corresponds to an observable activation free energy of $52.8 \mathrm{kcal} \mathrm{mol}^{-1}$. The barrier height for the direct attack of water on the carbonyl group is consistent with previous theoretical works, but considerably higher than the experimental value of 31.0

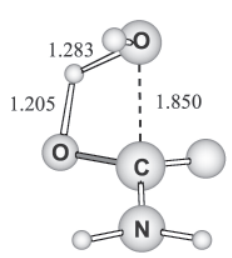

TS1a

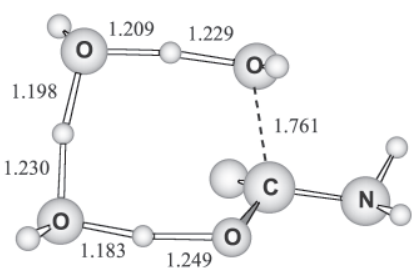

TS1c

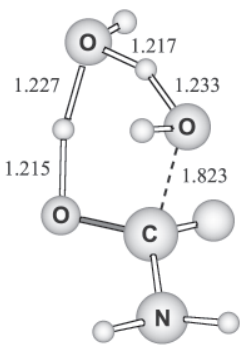

TS1b

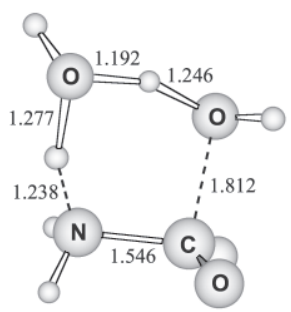

TS2b

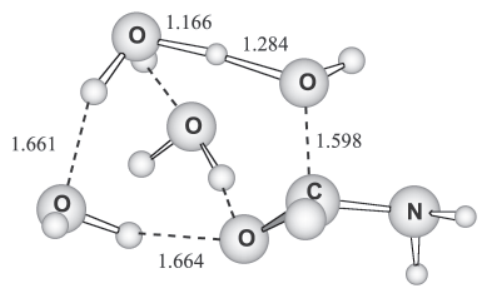

TS3d

Figure 1. Transition states for the reaction of $n \mathrm{H}_{2} \mathrm{O}$ with $\mathrm{HCONH}_{2}$ obtained at MP2/6-31G(d) level of theory.

$\mathrm{kcal} \mathrm{mol}^{-1}$. It can be noted that this barrier is fairly sensible to the level of theory.

The stepwise pathway involving two water molecules (TS1b) has a free energy barrier of $42.5 \mathrm{kcal} \mathrm{mol}^{-1}$ in the gas-phase and the inclusion of the bulk solvent increases the barrier to $53.5 \mathrm{kcal} \mathrm{mol}^{-1}$. The final observable activation free energy is $48.7 \mathrm{kcal} \mathrm{mol}^{-1}$. Thus, this modest catalytic effect of the additional water molecule is not able to lead to considerable rate acceleration. However, differently of TS1a, we can note a great sensibility of the barrier height with the level of theory. The activation energy increases from $15.7 \mathrm{kcal} \mathrm{mol}^{-1}$ at MP2/6-31G(d) level to $23.8 \mathrm{kcal}$ $\mathrm{mol}^{-1}$ at $\operatorname{CCSD}(\mathrm{T}) / 6-311+\mathrm{G}(2 \mathrm{df}, 2 \mathrm{p})$ level.

Inclusion of an additional water molecule in the cyclic transition state, corresponding to the TS1c structure, leads to an observable activation free energy barrier in solution of $51.5 \mathrm{kcal} \mathrm{mol}^{-1}$, higher than the reaction with only two water molecules. Even more interesting is the higher sensibility of the barrier in relation to the level of theory, which changes from $1.8 \mathrm{kcal} \mathrm{mol}^{-1}$ at MP2/6-31G(d) level to $14.6 \mathrm{kcal} \mathrm{mol}^{-1}$ at $\mathrm{CCSD}(\mathrm{T}) / 6-311+\mathrm{G}(2 \mathrm{df}, 2 \mathrm{p})$ level. As expected, this mechanism is entropicaly very unfavorable and the $-\mathrm{T} \Delta \mathrm{S}_{\mathrm{g}}^{\ddagger}$ term increases the barrier by $25 \mathrm{kcal} \mathrm{mol}^{-1}$. It occurs because there are four molecules into the transition state and the catalysis, although present, is not enough to favor this mechanism in aqueous solution because the cost for desolvating three water molecules and the formamide to form the transition state is also very high, increasing the barrier by $18 \mathrm{kcal} \mathrm{mol}^{-1}$. Therefore, the pathway through TS1b has the most adequate compromise between enthalpy, entropy and solvent effect to form the tetrahedral intermediate.

For the concerted mechanism, only the water-catalyzed pathway was investigated because previous works have shown that the direct attack of water is less favorable. The concerted water catalyzed transition state corresponds to structure TS2b. Similarly to transition state TS1b, the activation barrier through this structure is very sensible to the level of theory, increasing from $22.7 \mathrm{kcal} \mathrm{mol}^{-1}$ at MP2/6-31G(d) level to $33.6 \mathrm{kcal} \mathrm{mol}^{-1}$ at $\operatorname{CCSD}(\mathrm{T}) / 6$ $311+\mathrm{G}(2 \mathrm{df}, 2 \mathrm{p})$ level. As expected, TS2b is more stabilized by the solvent than TS1b because of its zwiterionic character and the electrostatic solvation increases the barrier only by $6.4 \mathrm{kcal} \mathrm{mol}^{-1}$. The observable activation free energy barrier is calculated to be $52.8 \mathrm{kcal} \mathrm{mol}^{-1}$.

We have also investigated another transition state, TS3d, which includes four explicit water molecules. In this structure, the addition of water is better seen as a general base catalysis by a second water molecule rather than bifunctional catalysis, since both the $\mathrm{H}_{3} \mathrm{O}^{+}$and $\mathrm{HC}\left(\mathrm{NH}_{2}\right)(\mathrm{OH}) \mathrm{O}^{-}$ions are generated. The formation of this 
Table 1. Activation energies and thermodynamic properties for the reaction $\mathrm{HCONH}_{2}+\mathrm{n}_{2} \mathrm{O}$ in aqueous solution

\begin{tabular}{|c|c|c|c|c|c|c|}
\hline & TS1a & TS1b & TS1c & $\mathrm{TS} 2 \mathrm{~b}$ & $\mathrm{TS} 2 \mathrm{~b}^{\mathrm{h}}$ & $\mathrm{TS} 3 \mathrm{~d}$ \\
\hline B3LYP/6-31+G(d) & - & - & - & - & 30.48 & \\
\hline $\mathrm{HF} / 6-31 \mathrm{G}(\mathrm{d})$ & 54.51 & 37.74 & 30.77 & 51.32 & - & 9.11 \\
\hline MP2/6-31G(d) & 40.56 & 15.67 & 1.84 & 22.71 & - & -20.76 \\
\hline MP2/6-311+G(2df,2p) & 41.05 & 20.69 & 9.69 & 29.36 & - & -5.18 \\
\hline $\operatorname{CCSD}(\mathrm{T}) / 6-31 \mathrm{G}(\mathrm{d})$ & 41.70 & 18.82 & 6.76 & 26.95 & - & -16.44 \\
\hline $\operatorname{CCSD}(T) / 6-311+G(2 d f, 2 p)^{b}$ & 42.19 & 23.84 & 14.62 & 33.61 & $35.02^{\mathrm{i}}$ & -0.85 \\
\hline$\Delta \mathrm{H}_{\mathrm{g}}^{\ddagger \mathrm{c}}$ & 41.93 & 25.21 & 16.32 & 34.67 & - & 7.37 \\
\hline$-\mathrm{T} \Delta \mathrm{S}_{\mathrm{g}}^{\mathrm{g}} \mathrm{g}$ & 8.62 & 17.32 & 24.90 & 17.23 & - & 32.36 \\
\hline$\Delta \mathrm{G}_{\mathrm{g}}^{\ddagger \mathrm{c}}$ & 50.55 & 42.53 & 41.22 & 51.90 & 52.36 & 39.73 \\
\hline$\Delta \Delta \mathrm{G}_{\text {solv-el }}^{\mathrm{g}} \stackrel{\mathrm{d}}{\mathrm{g}}$ & 5.13 & 11.79 & 18.00 & 6.38 & 2.21 & 25.59 \\
\hline$\Delta \Delta \mathrm{G}_{\text {solv-nel }}^{\text {solvel }}$ & -0.53 & -0.86 & -0.58 & -0.74 & -0.23 & -0.29 \\
\hline$\Delta \mathrm{G}_{\text {sol }}^{+}$ & 55.16 & 53.46 & 58.64 & 57.53 & 54.33 & 65.04 \\
\hline$\Delta \mathrm{G}_{\mathrm{obs}}^{\mathrm{f}} \mathrm{g}$ & 52.78 & 48.70 & 51.50 & 52.78 & 49.58 & 55.52 \\
\hline
\end{tabular}

${ }^{a}$ Standard state of $1 \mathrm{~mol} \mathrm{~L}^{-1}, 298.15 \mathrm{~K}$. Units of kcal mol${ }^{-1}$. Activation energies at different theoretical levels; ${ }^{\mathrm{b}}$ Obtained by additivity approximation; ${ }^{\mathrm{c}} \mathrm{Gas}-$ phase values based on the $\operatorname{CCSD}(\mathrm{T}) / 6-311+\mathrm{G}(2 \mathrm{df}, 2 \mathrm{p})$ energies; ${ }^{\mathrm{d}}$ Electrostatic contribution to the solvation free energy; ${ }^{\mathrm{e}}$ Nonelectrostatic contribution to the solvation free energy; ${ }^{\mathrm{f}}$ Activation free energy in aqueous solution; ${ }^{\mathrm{g}}$ Observable activation free energy in aqueous solution; ${ }^{\mathrm{h}} \mathrm{Geometries} \mathrm{obtained} \mathrm{at} \mathrm{PCM/}$ B3LYP/6-31+G(d) level; i Obtained by additivity approximation using MP2/6-31+G(d), MP2/6-311+G(2df,2p) and CCSD(T)/6-31+G(d) calculations.

ion pair is possible because there are two additional water molecules into the cluster able to stabilize the system. Nevertheless, even in this case the observable activation free energy barrier remains very high, $55.5 \mathrm{kcal} \mathrm{mol}^{-1}$. Because five molecules are involved into the transition state, the $-\mathrm{T} \Delta \mathrm{S}_{\mathrm{g}}^{\ddagger}$ term is the most important contribution for the free energy barrier in this case. Therefore, all of the mechanisms involving cyclic transition states (TS1a, TS1b, TS1c and TS2b) and the general base catalysis one (TS3d) have very high activation free energies.

The barrier heights for the mechanisms involving two, three and four water molecules are quite dependent on the level of theory. Thus, we have done single point calculations at MP2 level with the aug-cc-pVDZ, aug-cc-pVTZ and augcc-pVQZ basis sets in order to test the convergence of the activation barrier. Only the TS1b structure was considered and the results are in Table 2. As it can be observed, all these three basis sets as well as $6-311+\mathrm{G}(2 \mathrm{df}, 2 \mathrm{p})$ lead to activation barrier within $2 \mathrm{kcal} \mathrm{mol}^{-1}$, which suggest that the lack of diffuse functions in the 6-31G(d) basis set is critical.

Table 2. Activation energies for the reaction $\mathrm{HCONH}_{2}+2 \mathrm{H}_{2} \mathrm{O}^{\mathrm{a}}$

\begin{tabular}{ll}
\hline & TS1b \\
\hline MP2/aug-cc-pVDZ & 19.31 \\
MP2/aug-cc-pVTZ & 18.50 \\
MP2/aug-cc-pVQZ & 19.37 \\
B3LYP/6-31G(d) & 10.13 \\
B3LYP/6-311+G(2df,2p) & 22.89
\end{tabular}

${ }^{\mathrm{a}}$ Units of kcal mol${ }^{-1}$.

We have also investigated the performance of the B3LYP hybrid functional to describe this system (activation through TS1b, Table 2). The B3LYP/6-31G(d) level predicts a barrier of $10.1 \mathrm{kcal} \mathrm{mol}^{-1}$, in considerable deviation from our best level, $\operatorname{CCSD}(\mathrm{T}) / 6-311+\mathrm{G}(2 \mathrm{df}, 2 \mathrm{p})$, which predicts a barrier of $23.8 \mathrm{kcal} \mathrm{mol}^{-1}$. However, when the extended $6-311+\mathrm{G}(2 \mathrm{df}, 2 \mathrm{p})$ basis set is used with the B3LYP functional, the barrier increases to $22.9 \mathrm{kcal} \mathrm{mol}^{-1}$, in excellent agreement with our high level $\operatorname{CCSD}(\mathrm{T})$ calculations. This is an interesting result because it suggests that the B3LYP/6-311+G(2df,2p) level of theory is very accurate for studying nucleophilic addition to amides and probably, carbonyls in general.

\section{The role of liquid-phase geometry optimization}

In this work, we are using gas-phase-optimized geometries to determine the activation thermodynamic properties of a process taking place in liquid phase. We could ask how the solvent changes the geometries and, consequently, the activation barriers? Usually, gas-phase optimized geometries are reliable for modeling liquid phase reactions involving neutral species, but it could be less accurate for ionic reactions. In the present system, we are considering the transition state (TS2b) that presents a considerable charge separation. Thus, the solvent could play an important role on the geometry.

In order to verify the solvent effect in the geometries, we have investigated the reaction through TS2b at PCM/ B3LYP/6-31+G(d) level of theory and also included optimizations at gas-phase B3LYP/6-31+G(d) level for comparison. The optimized geometry is presented in Figure 2, as well as, the most important geometrical parameters. As it can be noticed, in this case, there is a considerable variation of the geometry in relation to the gas-phase. For example, the carbon-oxygen distance in 


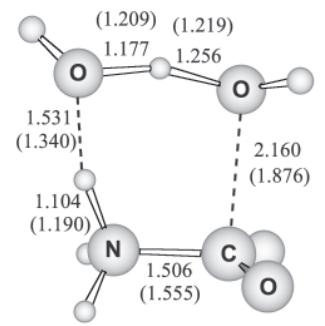

TS2b

Figure 2. Transition state for the reaction of $2 \mathrm{H}_{2} \mathrm{O}$ with $\mathrm{HCONH}_{2}$ obtained at PCM/B3LYP/6-31+G(d) level of theory. The values in parentheses correspond to geometry obtained at gas-phase B3LYP/6-31+G(d) level of theory.

TS2b is $1.876 \AA$ in gas-phase and becomes $2.160 \AA$ in solution. For comparison, at gas-phase MP2/6-31G(d) level the distance is $1.812 \AA$, fairly close to gas-phase B3LYP/6-31+G(d) calculation. The activation barrier decreases by $3 \mathrm{kcal} \mathrm{mol}^{-1}$ in relation to gas-phase MP2/6$31 \mathrm{G}(\mathrm{d})$ geometry and becomes $49.6 \mathrm{kcal} \mathrm{mol}^{-1}$. Thus, it is evident that even in this case, where the solvent effect on the geometry is expected to be more important, its effect on the barrier is not very high. In fact, it is much less important than the level of the gas-phase energy calculations where differences around $10 \mathrm{kcal} \mathrm{mol}^{-1}$ were observed.

\section{Discussion}

The neutral hydrolysis of amides is very hard to observe experimentally. The reaction is slow and requires high temperatures. In many cases, it is not evident if the neutral hydrolysis really takes place as in the case of formamide. In the present work, we have analyzed five different transition states for the neutral hydrolysis of formamide. For all cases, it was found a very high activation free energy barrier. The most stable structure is the TS1b (Figure 1), corresponding to the stepwise water catalyzed mechanism and having an activation free energy barrier of $48.7 \mathrm{kcal} \mathrm{mol}^{-1}$. This barrier implicates in a very slow and unobserved kinetics. In addition, we have tested the convergence of the calculations using very extended basis sets and these additional calculations support a high barrier for TS1b. The role of the solvent on the geometries were also investigated and it was found that liquid phase optimization decreases the barrier of TS2b by $3 \mathrm{kcal} \mathrm{mol}^{-1}$. For comparison, the level of theory has a much larger effect on the activation barrier. Thus, we can claim that our calculations predict that the neutral hydrolysis does not take place in aqueous solution.

In a recent work, $\mathrm{Zahn}^{28}$ reported a Car-Parrinelo Molecular Dynamics calculation of the neutral hydrolysis of N-methylacetamide and found a barrier of $35 \mathrm{kcal} \mathrm{mol}^{-1}$ for the hydrolysis through a mechanism similar to the concerted water catalyzed one. Although a very sophisticate method with full quantum-mechanical treatment of the solvent was used, our study shows that density functional theory with small basis set is not accurate for water catalyzed amide hydrolysis. In fact, if we take the B3LYP/6-31G(d) energies in order to calculate the barrier for the amide hydrolysis through TS1b, the free energy barrier becomes $35 \mathrm{kcal} \mathrm{mol}^{-1}$, in close agreement with Zhan calculations, but very different of the higher level $\operatorname{CCSD}(\mathrm{T}) / 6-311+\mathrm{G}(2 \mathrm{df}, 2 \mathrm{p})$ calculation, $48.7 \mathrm{kcal} \mathrm{mol}^{-1}$. In order to obtain a reliable activation free energy, both the gas-phase energies and the solvent effect needs to be accurate. An additional point to notice is the use of $1 \mathrm{~atm}$ standard state. Even using this standard state, the barrier remains very high, $52.5 \mathrm{kcal} \mathrm{mol}^{-1}$. Thus, we believe that the calculation of Zahn is not sufficient for an accurate treatment of the transition state and the calculated barrier is considerably underestimated.

Taken together, our results point out that the kinetics of the formamide neutral hydrolysis is very slow and it should not be observed in aqueous solution. Only the base and acid hydrolysis would be significant. For comparison, Pliego has recently reported a theoretical calculation of the base hydrolysis of formamide in aqueous solution, ${ }^{29}$ obtaining a $\Delta \mathrm{G}^{\ddagger}$ of $23.4 \mathrm{kcal} \mathrm{mol}^{-1}$, only $2.2 \mathrm{kcal} \mathrm{mol}^{-1}$ above of the experimental value. This study point out the reliability of the theoretical methods utilized. As additional evidence, it could be noticed that the neutral hydrolysis of formamide was not isolated of the acid and base hydrolysis even measuring the reaction rate in different temperatures. It was argued that this property is due to similar variation of the autoprotolysis constant of water, providing different concentration of hydroxide ion, which competes with the neutral hydrolysis. ${ }^{4}$ In our opinion, such coincidence is highly improbable and this observation is further indication that the neutral hydrolysis of formamide does not take place at all. Thus, we leave a problem for the experimentalists: to design an experiment able to provide a definitive conclusion. One possibility is to carry out the reaction in a mixture of water with dimethyl sulfoxide, because this medium would decrease the autoionization of water and as a consequence, it would also decrease the interference of the $\mathrm{H}_{3} \mathrm{O}^{+}$and $\mathrm{OH}^{-}$ions. If the neutral hydrolysis is really significant, it should be observed.

\section{Conclusion}

We have reported a theoretical study of the neutral hydrolysis of formamide in aqueous solution involving 
up to four explicit water molecules in the transition state and including a continuum solvation model. Based on our calculated activation free energy barrier, we conclude that the neutral hydrolysis of formamide does not take place at all. The $\mathrm{k}_{\mathrm{w}}$ term reported in the literature is not a real rate constant, but a mathematical artifact originated of the fitting process.

\section{Acknowledgments}

The authors thank the Conselho Nacional de Pesquisa (CNPq) for the Profix program support.

\section{References}

1. Brown, R. S.; Bennet, A. J.; Slebocka-Tilk, H.; Acc. Chem. Res. 1992, 25, 481.

2. Johnson, S. L.; Adv. Phys. Org. Chem. 1967, 5, 237.

3. Slebocka-Tilk, H.; Rescorla, C. G.; Shirin, S.; Bennet, A. J.; Brown, R. S.; J. Am. Chem. Soc. 1997, 119, 10969.

4. Slebocka-Tilk, H.; Sauriol, F.; Monette, M.; Brown, R. S.; Can. J. Chem. 2002, 80, 1343 .

5. Hine, J.; King, R. S. M.; Midden, W. E.; Sinha, A.; J. Org. Chem. 1981, 46, 3186.

6. Cascella, M.; Raugei, S.; Carloni, P.; J. Phys. Chem. B 2004, 108, 369.

7. Kallies, B.; Mitzner, R.; J. Mol. Model. 1998, 4, 183.

8. Pitarch, J.; Ruiz-Lopez, M. F.; Silla, E.; Pascual-Ahuir, J. L.; Tunon, I.; J. Am. Chem. Soc. 1998, 120, 2146.

9. Pitarch, J.; Ruiz-Lopez, M. F.; Pascual-Ahuir, J. L.; Silla, E.; Tunon, I.; J. Phys. Chem. B 1997, 101, 3581.

10. Antonczak, S.; Ruiz-Lopez, M. F.; Rivail, J. L.; J. Am. Chem. Soc. 1994, 116, 3912.

11. Jensen, J. H.; Baldridge, K. K.; Gordon, M. S.; J. Phys. Chem. 1992, 96, 8340.

12. Krug, J. P.; Popelier, P. L. A.; Bader, R. F. W.; J. Phys. Chem. 1992, 96, 7604.

13. Oie, T.; Loew, G. H.; Burt, S. K.; binkley, S. K.; MacElroy, R. D.; J. Am. Chem. Soc. 1982, 104, 6169.

14. Pliego Jr., J. R.; Chem. Phys. Lett. 2003, 367, 145.

15. da Silva, C. O.; da Silva, E. C.; Nascimento, M. A. C.; Chem. Phys. Lett. 2003, 381, 244.
16. Pliego Jr., J. R.; Chem. Phys. Lett. 2003, 381, 246.

17. Tomasi, J.; Mennucci, B.; Cammi, R.; Chem. Rev. 2005, 105 , 2999.

18. Cossi, M.; Barone, V.; Cammi, R.; Tomasi, J.; Chem. Phys. Lett. 1996, 255, 327.

19. Tomasi, J.; Persico, M.; Chem. Rev. 1994, 94, 2027.

20. Cances, E.; Mennucci, B.; Tomasi, J.; J. Chem. Phys. 1997, 107, 3032.

21. Mennucci, B.; Cances, E.; Tomasi, J.; J. Phys. Chem. B 1997, 101, 10506.

22. Pliego Jr., J. R.; J. Braz. Chem. Soc. 2005, 16, 227.

23. Granovsky, A. A. http://classic.chem.msu.su/gran/gamess/ index.html accessed in March 2003.

24. Schmidt, M. W.; Baldridge, K. K.; Boatz, J. A.; Elbert, S. T.; Gordon, M. S.; Jensen, J. H.; Koseki, S.; Matsunaga, N.; Nguyen, K. A.; Su, S.; Windus, T. L.; Dupuis, M.; Montgomery Jr., J. A.; J. Comput. Chem. 1993, 14, 1347.

25. Piecuch, P.; Kucharski, S. A.; Kowalski, K.; Musial, M.; Comput. Phys. Commun. 2002, 149, 71.

26. Piecuch, P.; Kowalski, K.; Pimienta, I. S. O.; McGuire, M. J.; Int. Rev. Phys. Chem. 2002, 21, 527.

27. Frisch, M. J.; Trucks, G. W.; Schlegel, H. B.; Scuseria, G. E.; Robb, M. A.; Cheeseman, J. R.; Zakrzewski, V. G.; Montgomery Jr., J. A.; Stratmann, R. E.; Burant, J. C.; Dapprich, S.; Millam, J. M.; Daniels, A. D.; Kudin, K. N.; Strain, M. C.; Farkas, O.; Tomasi, J.; Barone, V.; Cossi, M.; Cammi, R.; Mennucci, B.; Pomelli, C.; Adamo, C.; Clifford, S.; Ochterski, J.; Petersson, G. A.; Ayala, P. Y.; Cui, Q.; Morokuma, K.; Malick, D. K.; Rabuck, A. D.; Raghavachari, K.; Foresman, J. B.; Cioslowski, J.; Ortiz, J. V.; Baboul, A. G.; Stefanov, B. B.; Liu, G.; Liashenko, A.; Piskorz, P.; Komaromi, I.; Gomperts, R.; Martin, R. L.; Fox, D. J.; Keith, T.; Al-Laham, M. A.; Peng, C. Y.; Nanayakkara, A.; Challacombe, M.; Gill, P. M. W.; Johnson, B.; Chen, W.; Wong, M. W.; Andres, J. L.; Gonzalez, C.; HeadGordon, M.; Replogle, E. S.; Pople, J. A. Gaussian 98. [A.9]. 1998. Pittsburgh PA, Gaussian, Inc.

28. Zahn, D.; Eur. J. Org. Chem. 2004, 4020.

29. Pliego Jr., J. R.; Chem. Phys. 2004, 306, 273.

Received: June 29, 2005

Web Release Date: June 15, 2007 